compiled by Suzanne Wise

*Lagniappe (lăn-yăp’’, lăn’ yăp’) n. An extra or unexpected gift or benefit. [Louisiana French]

\title{
NC ECHO: More Than a Web Portal A Comprehensive Access to Special Collections and Digitization Program
}

\author{
by Thomas Kevin B. Cherry
}

$\mathbf{Y}$

ou can listen to the Harmony Singers from Dutch Cove's Morning Star Methodist Church sing "Pisgah," shape-note style. You can browse the 1914 business directory of New Bern and there read about that new "delicious and healthful drink" created and bottled locally known as Pepsi-Cola. You can study photographs of North Carolina students from the state's mule-powered years as they sit astride fallen trees, pose alongside creeks, and generally help give the world professional forestry. You can scroll through Women's Army Corps medals and memorabilia from World War II. You can take a quick look at a picture of a mid-1970s Krispy Kreme counter, the fare lined up and looking "hot now." You can flip through the pictures that show what little was left of the Johnston County tavern/ service station known as "Catch-Me Eye" after a passing munitions truck exploded nearby early one March morning in 1942. You can study the finding aids of more than 1,000 manuscript collections held by East Carolina University's special collections (with materials from former Confederate generals to WWI-era tea merchants in China). You can listen as Arthur Goodman talks about the experiences of Charlotte's close-knit Jewish community during the Depression. You can read the 1863 letter of Flatrock's Emma Shoolbred to Col. Joseph Cathey, as the widowed woman asks his help in finding war-scarce corn and an ox. You can tour the historic architecture of Wilmington by time period, architectural style, or builder. You can skim through the 1820s diary of Baptist leader and founder of Wake Forest University, Samuel Wait. You can marvel at the near-poetic images of Wilmington's World War II army artist Henry Jay MacMillan. In short, you can more easily visit North Carolina's past thanks to NC ECHO.

North Carolina ECHO (Exploring Cultural Heritage Online), a collaborative undertaking of the state's cultural heritage agencies, is the statewide access to special collections and digitization program sponsored by the State Library of North Carolina. ${ }^{1}$ Since its founding in late 1999 , the program has created a Web portal to the state's cultural heritage repositories (archives, libraries, and museums), identified standards and best practices for digitization, established a two-tiered continuing education program, and, as a needs assessment, launched one of the most comprehensive surveys of cultural collecting agencies ever attempted by a state. NC ECHO has also crafted a multi-level grant program using federal Library Service and Technology Act (LSTA) funds to help build sustainable digital capabilities at the local level, while providing libraries and their partners with the necessary resources to make some of their special collection material available over the Internet. ${ }^{2}$ 


\section{Portal}

North Carolina can claim museums of cut glass, taxidermy, and several that are NASCAR-related, among many others. It has libraries filled with rare books, literary manuscripts, and genealogical files. It holds archives bulging with diaries, old photographs, and sound recordings. North Carolina's "memory" institutions now number somewhere near 900. NC ECHO's comprehensive "directory function" provides contact information and links to individual Web sites for all of these institutions, from the largest of government-supported libraries to the smallest, volunteer-run, cross-roads museum. As long as a North Carolina institution maintains a "permanent, non-living collection of unique materials for research and or exhibit purposes," that institution is going to be on NC ECHO. This directory of collecting agencies can be searched alphabetically by institution name, county or city of origin, type of institution (art museum, children's museum, genealogical society, etc.), or collection strength. For those institutions that do not have their own Web site, NC ECHO provides a much-needed Internet presence. As a result, $\mathrm{NC}$ ECHO is a good resource for those seeking experts on local historical and cultural subjects.

In perhaps its best-known function, NC ECHO's Web portal $<$ www.ncecho.org $>$ also provides access to the digitized holdings mounted by the state's cultural repositories. These materials can include streaming audio of oral history interviews, digital copies of archival materials, images of museum items, and transcribed (and/or digitized) versions of hard-to-come-by printed items. Not all of these resources have been digitized utilizing NC ECHO grant funds; some have benefited from other grant pro-

NC ECHO's Web portal provides access to the digitized holdings mounted by the state's cultural repositories. grams and others have been created out of operating budgets, but no matter the funding source, NC ECHO brings these unique materials together in one Internet space. Among these online materials are the holdings of the University of North Carolina at Chapel Hill's internationally well-regarded Documenting the American South, which holds, among other materials, transcriptions of every known North American slave narrative. ${ }^{3}$ No matter how small a library might be or how remote, if it has access to the Internet, its users have at their fingertips the same number of slave biographies and autobiographies as any major academic library; it has them all. Duke University's famous papyrus archive makes more than 1400 small strips of some of humankind's earliest writing available to the public as well. Now school children doing their "Ancient Egypt" projects can look over the same items that were once only consulted by academicians. ${ }^{4}$ East Carolina University's North Carolina History and Fiction Digital Library is currently in the beginning stages, but it already makes 170 titles (more than 23,000 pages of text) on eastern North Carolina subjects available to Internet researchers-from county histories, to works on pirates, to Burnside's Civil War era expedition. Also among this digital library's titles are a number of useful maps (turn-ofthe century, geological survey and Civil War-related) and hard-to-find, early pieces of fiction set in the Old North State. ${ }^{5}$

Academic libraries aren't the only institutions creating online resources. When one of its local treasures became too fragile for regular handling, the Union County Public Library chose to make a digital copy available via the World Wide Web. Now, anyone with Internet access can consult the Heroic Sons of Gold Star Mothers' Scrapbook, the county's unofficial memorial to its young men lost in World War II. With a page devoted to each of the fallen, their dates of induction, medals received, and photographs, this item is among the most touching of tributes, and in some ways tells war's sacrifices better than any stone obelisk ever could. ${ }^{6}$ The Robinson-Spangler Carolina Room of the Public Library of Charlotte and Mecklenburg County has mounted, among several Web publications, People on the Hill, an online photographic exhibit of Charlotte's Highland Park Mill Community. In these photographs can be seen the past of many North Carolina families, whether 
they lived in Charlotte, Kannapolis, or Rocky Mount, because here the Carolina mill family is captured in black and white. The Greensboro Historical Museum's Slavery as We Heard It is an online reproduction of the oral history project completed in 1932 by Jonesboro Elementary School students who interviewed their parents and grandparents, many of whom were former slaves. Slowly, thanks to the Internet, librarians, archivists, and museum specialists are able to reveal treasures protected by locked cabinets and closed stacks and make them more available to their users.

Each of the sites mentioned above can be accessed directly. Union County Public Library's scrapbook is found on the library's Web site and Documenting the American South's slave narratives are found on the UNC-CH library site. Each of the individual institutions, while making these items available on their own sites, have also been following digitization standards that will eventually allow a user to employ a central search tool to scan the spectrum of digitized resources made available by North Carolina cultural institutions. NC ECHO is making that central search tool possible. With such a tool, an eighth grader doing his North Carolina history project on World War I will be able to type "World War I" into an NC ECHO search box and retrieve images of recruitment posters, uniforms, and other artifacts made available by UNC-CHrelated government publications mounted by the State Library of North Carolina, and images of Camp Greene digitized by the Public Library of Charlotte and Mecklenburg County. This centralized search tool is currently under development. Until its creation, the NC ECHO staff is "cataloging" North Carolina's digitization projects by assigning Library of Congress subject headings to online collections of materials. These subject headings are listed on the NC ECHO site and linked directly to the Web resource. These links currently provide the only inter-institutional access to the state's online cultural heritage resources. While this mechanism provides useful inter-institutional and online collection access, NC ECHO's full promise will not be met until its more robust searching mechanism is fully developed. ${ }^{7}$

\section{Standards/Best Practices}

To ensure interoperability between digitization projects (such as centralized search tools) and the long-term preservation of digital materials, NC ECHO has based its work on international standards and tested best practices. Because digitization is labor intensive and originals are often fragile, NC ECHO adopted the "Scan Once" methodology. This methodology means that digitizers scan source material at high resolutions and store the unaltered resulting master images in such a manner that they can be re-used in the future. ${ }^{8}$ As an example, to digitize a photograph, one would scan the item at $600 \mathrm{dpi}$, 24-bit, RGB color and save it in an uncompressed format (TIFF). Such a resolution might take up a bit of hard drive, CD or DVD space, but space is cheap when compared to the cost of re-scanning. In addition, high-resolution images are more flexible than their low resolution counterparts; they can be bent to multiple purposes, and because they hold more information, they hold greater potential-for print publications, zooming, etc. Surrogates of these highly flexible master images can be created for more practical, single purposes such as Web access. It's all about scanning once and re-using surrogates of that original scan, a durable, high-resolution, master image.

A person can create as many high-resolution durable images as he or she likes, mounting all the resulting lower-quality surrogates (thumbnails) on the Web, but if a user can't find and retrieve them, then all of that work amounts to little. To allow for interoperability and more effective retrieval of digital information, NC ECHO staffers promote the Metadata First approach to digitization. Metadata, in the most general sense, is data about data. Traditional cataloging information is one form of descriptive metadata. It provides information (subject, author, title) about other information (the book) so that the latter can be more easily stored and retrieved. When information is in digital form, the amount and type of supporting information (metadata) required to preserve, store, and retrieve that initial information often is more complex. 
For example, when a person digitizes a book, some information needs to be created and associated with the digital copy so that the user will know the order of the resulting electronic pages. Page order is not something that catalogers of printed material have to worry about all that often. Another example: metadata that records the type of program used in the creation of an electronic item or the form in which that item is stored might be information required to preserve the original for the long term. Preservation requirements for a book are not generally added to a cataloging record.

When a general consensus develops about the rules for such practices as the correct way to alert readers to page order or the most appropriate information to gather for long-term preservation, then a metadata standard of some variety is beginning to evolve. NC ECHO has identified and promotes a number of interrelated metadata standards. For example, if an NC ECHO partner is transcribing a book, pamphlet or other printed item, it is encouraged to use the Text Encoding Initiative (TEI), which is a standardized way of marking up transcriptions to show where pages in the original end, etc. ${ }^{9}$ If an NC ECHO partner is attempting to make a manuscript or archival finding aid available over the Internet, it is encouraged to use Encoded Archival Description (EAD). ${ }^{10}$ In addition, there are metadata standards for describing works of art, maps, and other, more specialized resources. Through the process of matching related descriptors (or fields) from one of these metadata schema to the related descriptors (or fields) of another metadata scheme (a process known as crosswalking), it is possible to retrieve and collate related items. ${ }^{11}$ For example, a book might have an "author" in one metadata scheme, and a work of art might have a "creator" in another. One form of crosswalking might merge these two fields in retrieval, bringing authors and creators together in the search results. The least complex metadata scheme currently in use is Dublin Core, which uses sixteen basic fields for description. Since these fields are so general, they can be used to describe just about anything. Because of this, Dublin Core has been called the "big tent" of metadata; almost all other more specialized schema can fit underneath its highly general folds. NC ECHO takes advantage of Dublin Core's lack of specificity, and requires that partner institutions supply at least the basic Dublin Core information for their online creations. ${ }^{12}$ By doing so, the institutions ensure that future users will have at least sixteen access points to digitized creations. If the institution wishes to use a more specialized form of metadata, then certain fields from that scheme will simply be crosswalked to the more general Dublin Core. Of course, where possible, NC ECHO partners are encouraged to relate their digitized materials to one of the most thorough and specific metadata standards, MARC.

To support North Carolina's cultural agencies in the use of all-important metadata, NC ECHO hired a metadata coordinator for the state, Kathy Wisser. She provides continuing education opportunities for North Carolina's cultural caretakers, serves as staff to the various NC ECHO-associated metadata working groups, and provides one-on-one consultations with librarians, helping them address both programmatic and item-specific metadata challenges. ${ }^{13}$ Along these same lines, NC ECHO has also adopted tools to aid in the use of metadata, bringing to the state's cultural repositories both Dublin Core and EAD templates. ${ }^{14}$ With a little training, these tools, and a bit of guidance from the metadata working groups and coordinator, cultural caretakers can readily meet the standards that give interoperability to their digital creations.

\section{Continuing Education}

People aren't born knowing about metadata. Scan Once Methodology isn't something that your average local history librarian stumbles upon on his own. Because of this, from the beginning NC ECHO has provided a multilevel continuing education program. Since digitization builds upon the foundation of traditional arrangement, description, and preservation, not every 
cultural institution in the state is ready to make digital copies of its original materials. Institutions have "good stuff"; it's just in bad shape: no acid-free enclosures, little in the way of arrangement and less in description. ${ }^{15}$ Many of the institutions that hold material in this state are volunteer-run, and their staffs need training in the basics. To meet their needs, NC ECHO annually joins the Federation of North Carolina Historical Societies in presenting one level of continuing education, Hometown History workshops. These day-long workshops are held regionally, cost little, and have covered topics from basic arrangement and preservation of archival materials to first steps in fundraising. Hometown History, originally a series created by the North Carolina Library Association's Round Table on Special Collections, has benefited local historical and genealogical societies in particular since their volunteers are always changing, leaving a steady stream of newcomers waiting to be trained.

On another level, NC ECHO meets the needs of those institutions that are ready to run the scanners. For those libraries, archives, and museums with collections that already have foundations of traditional access and preservation, NC ECHO sponsors a week-long, highly intensive Digitization Institute. The cost of attendance at this institute, which is available through an application process, is supported by federal LSTA funds. ${ }^{16}$ The Digitization Institute emphasizes project planning and sustainability while offering opportunities to learn and practice standard digitization practices through hands-on activities. NC ECHO also sponsors workshops on a wide array of metadata issues, with particular emphasis on Encoded Archival Description (EAD). There are classes in basic EAD, advanced EAD, and sometimes both offered consecutively. Currently in the making is a "Workshops to Go" program, in which local institutions alert NC ECHO staff to their continuing education needs, and NC ECHO then locates the most appropriate individual(s) to present instruction tailored to meet those needs. ${ }^{17}$ This ambitious multi-level continuing education program has been successful in training a wide array of cultural caretakers in the latest advances and most time-tested techniques. Much of this success can be attributed to a number of institutions and individuals around the state who have been willing to share their expertise with their colleagues.

\section{Needs Assessment}

What, exactly, is in the storage rooms of North Carolina's cultural collecting agencies? Where are all of those agencies located for that matter? What state of preservation do their collections enjoy? How much "stuff" do they hold? What are their education needs? When representatives of North Carolina's cultural repositories met in High Point in 1999 to advise NC ECHO's planners on the initial goals for the project, they had numerous questions about the state of North Carolina's memory institutions. To answer those questions, they suggested a comprehensive survey. What evolved was a 17-page survey instrument based on the New York State Historical Records Advisory Board's 1997 survey of historical repositories. ${ }^{18}$ Because the survey form was daunting, and it was anticipated that some institution might benefit from informal consultations, a survey team consisting of an archivist and a librarian was created to conduct on-site survey visits. Project Archivist Kim Cumber and Project Librarian Scott Reavis hit the road in March of 2001, first visiting the libraries and museums of Davie and Davidson Counties. ${ }^{19}$

On these survey visits, the staff reviews the survey instrument with representatives of the local institution, take photographs of the institution and its holdings that capture what might not be revealed by survey statistics, and provide on-site, informal consultations from basic preservation procedures to database design. NC ECHO survey staff has been particularly adept at strengthening the network between the state's cultural caretakers. This is a process that has been aided by "survey summary meetings." In these meetings, representatives of several local cultural institutions in one geographic area come together to hear the results of the survey, learn about activities tak- 
ing place at their respective institutions, and discuss ways in which they might collaborate in the future. In addition to sharing survey information, these meetings help build community between the state's cultural caretakers and strengthen avenues of communication, taking the first steps toward what might later evolve into the greater interoperability of their digitized holdings.

Currently, the NC ECHO survey staff has visited all but 18 counties in the state. When the survey began, NC ECHO maintained a list of approximately 550 cultural repositories. More than 300 other institutions have since joined that list. They stretch 888 miles from the Museum of the Cherokee in Murphy to the Roanoke Island Festival Park in Manteo. The survey team is still, sporadically, on the road and completing the survey. A final report, based on the survey's results, the photographs, and brief site visit reports, will be written at the survey's completion. It is anticipated that this report will be among the most thorough studies of the state's cultural agencies, perhaps surpassing the work of the WPA's state survey during the Great Depression.

\section{The Grant Program}

Beginning with two test grants in its initial year, NC ECHO has crafted a three-tiered grant program to provide libraries and their collaborating partners with the resources needed to digitize portions of their holdings, making them accessible via the Internet. The overall grant program, a part of the Library Service and Technology Act (LSTA) Grant Program managed by the State Library of North Carolina, is designed to aid institutions in building their own capacity to digitize materials, with the hope that many of these institutions will move from individual digitization projects to sustainable digitization programs. The first step toward that digitization program for a number of institutions is the EZ Digitization Starter Grant. This grant, like others in the State Library's LSTA EZ category, enjoys a simplified application project. (It does not require applicants to file letters of intent or meet matching requirements, for example.) While current figures for the present grant cycle have not been published, Starter Grants provide funds (up to $\$ 8,000$ in previous years) to libraries so that they can purchase basic digitization equipment (computers and scanners) and software (Adobe Photoshop, among others), as well as receive training in digitization techniques. Those institutions receiving Digitization Starter Grants in the past have been required to send staff members to the NC ECHO Digitization Institute. Grant recipients also agree to use the equipment and training to mount modest digitization projects in a single year, following NC ECHO guidelines. In short, Starter Grants are designed to help institutions with limited digitization experience "get started." Albemarle Regional Library, Greensboro Public Library, Guilford College's Hege Library, Meredith College's Campbell Library, the North Carolina Museum of Natural Science's Brimley Library, and Wayne County Public Library all received Starter Grants in the 2004-2005 cycle. ${ }^{20}$

NC ECHO Digitization Grants "encourage the use of digital technologies to improve access to the unique cultural holdings of North Carolina's libraries, museums, archives and historical societies." This grant program is intended to provide the resources to libraries with experience in digitization so that they can create quality online content that "reflects the rich diversity of cultural resources held by the state's institutions and the people who created them," prepare online finding aids for archival or manuscript materials, build partnerships for digitization with other cultural agencies, and incorporate metadata into digital creations. The maximum amount awarded by this grant program to a single library is $\$ 50,000$. If a library is involved in a collaborative project with another institution, the amount grows to $\$ 75,000$. There is a minimum grant award of $\$ 10,000$ and a $10 \%$ match is required. Beaufort County Community College, UNC-Asheville's Ramsey Library, UNC-Chapel Hill's Davis Library, Wake Forest University's Z. Smith Reynolds Library, Western Carolina University's Hunter Library, and the State Library of North Carolina all received grants in this category in 2004-2005, most as lead library 
agencies in collaborative projects. ${ }^{21}$ Beginning with the 2005-2006 fiscal year, the NC ECHO Digitization Grants may be multi-year undertakings.

NC ECHO Heritage Partner Grants, awarded for the first time in the 20042005 grant cycle, are intended to provide resources to libraries and their partners "to create online collections important to the history and cultural heritage of North Carolina," such as (but not limited to) "tobacco, textiles, the furniture industry, NASCAR, aviation, athletics, women's history, the civil rights movement, African Americans, Native Americans, and higher education." Applications for Heritage Partner Grants are considerably strengthened by including activities that support the state's educational programs. This is a multi-year grant program and requires that the lead library work collaboratively with partner institutions, including at least one non-library institution such as a museum. To qualify for a Heritage Partner Grant, applicants must have substantial experience in digitization, and since this grant program is intended to fund complex, multi-institutional projects, applicants must have first completed an LSTA Project Planning Grant. The maximum grant amount awarded is $\$ 150,000$ annually, with a minimum grant of $\$ 25,000$ per year, for up to three years. A $10 \%$ match from the recipient institutions is required. The first and only Heritage Partner Grant awarded so far has been to East Carolina Univ-ersity's "North Carolina History and Fiction Digital Library." Partners in this project include Historic Hope Foundation, the Tobacco Farm Life Museum, and the Country Doctor Museum.

Since the creation of its grant program, 28 digitization projects have been completed with NC ECHO grant funds with at least 13 more in process. Many of the state's cultural heritage institutions had no experience whatsoever with digitization before receiving their first NC ECHO grants. Several have graduated from Starter Grants to Digitization Grants, and one institution, East Carolina University, which had no experience in cultural heritage digitization four years ago, now has developed a full, on-going digitization unit within its library, a unit which recently received national recognition by a leading digitization corporation. In four years, East Carolina has moved from a simple $\$ 5,000$ grant project to being the lead agency in a multi-year Heritage Partner Grant.

\section{Collaboration}

The barriers that divide libraries, museums, and archives begin to break down when these institutions take their services to the Web. Museums, long islands of independent activity-especially with regard to their registration (cataloging) practices - begin to worry, library-like, about interoperability and controlled vocabulary when their collections near the Internet. Archives and libraries, understanding how users appreciate more contextual/interpretive information alongside their online materials, begin to act like museums when they near the Internet by providing labels and exhibits of library materials. ${ }^{22}$ Libraries and museums, like archives, begin to understand the importance of context and structure of information when they move toward the Web. All three types of cultural institutions become forms of information agencies online, and the media through which they share their information begin to resemble one another. Where does a book in an online exhibit start becoming a museum object and where does it stop being a book? Fortunately, few folks care. NC ECHO recognized this fact early on.

Thanks to digital technologies, it is now possible to bring together in one Internet space representations of museum objects, library items, and archival materials, and have them together become a new sort of publication or digital creation. Thanks to digital technologies, it is now possible to rejoin collections of materials that have been separated over time (the papers of a politician or writer, for example) or introduce collections that have never been near one another but whose subject is so closely related that they should have enjoyed the close proximity of a nearby shelf long before. Thanks to digital technologies, cultural heritage materials can now do tricks and jump through hoops with the ease of a mouse clicking. They can expand or zoom 
before the user's eye. They can be keyword searched. They can enjoy the running commentary of readers in hyper-Talmudic fashion. But for these potentialities and others not yet imagined to take place, the expertise and resources of multiple institutions must be brought together just as these institutions' materials find each other in cyberspace. Museum professionals and librarians rarely speak unless it is in the hall outside some funding agency's door. Archivists and librarians, despite often sharing the same roofs, speak different professional languages. Recognizing that collaboration between cultural heritage agencies is key if cultural heritage digitization is to reach its full potential (if for no other reason than a great deal of labor lies before us all and the more hands involved, the better), NC ECHO early on stressed the importance of collaboration. This emphasis is revealed by the fact that the program, although growing out of a State Library Commission report, is not simply a library digitization program. From the beginning, advisors to NC ECHO have represented a wide range of the state's cultural repositories. NC ECHO's advisory body, the Access to Special Collections Work Group (ASCWG), is composed of archivists, museum specialists, and librarians from a variety of institutions. ${ }^{23} \mathrm{NC}$ ECHO's portal points to cultural heritage agencies no matter what type of institution. Most of NC ECHO's continuing education is open to any cultural heritage professional. The strengthening of professional networks is built in to the NC ECHO survey process, and the NC ECHO grant program is designed to encourage collaboration.

\section{Decentralization}

One of the first core principles of NC ECHO is that North Carolina's statewide access to special collections and digitization program will be de-centralized. Other, major collaborative digitization programs in the nation have created centralized digitization teams that receive originals of cultural heritage materials, digitize them, and return the originals. Still other model programs have created centralized databases of items created in regional digitization centers. Local agencies create digital information based on their own holdings, then post that information to a central repository and descriptive system. NC ECHO planners, drawing upon the input of nearly 100 representatives of the state's cultural heritage community, felt that it was best to provide the state with widespread digitization capabilities rather than rely up a highly trained core of experts. Digitization as a cultural heritage activity, these planners felt, was here to stay. As such, local institutions should develop their own experts and capabilities. Some institutions would choose to create their own projects, while others would build programs. At the same time, however, there was an understanding that despite this independent work, the state's cultural heritage agencies together should provide the resources and infrastructure to support each other in their individual activities. NC ECHO's portal, standards support, survey, continuing education and grant programs are the formal part of the infrastructure that was crafted, but it is not the full infrastructure. Perhaps the most significant portion of that infrastructure lies in the informal day-to-day interaction of the state's cultural caretakers as they work together to provide the citizens of North Carolina and their world neighbors with the very best access to the holdings of the state's libraries, archives, and museums.

There are treasures in North Carolina. And no quick or easy process or project will make them more accessible to the people who own them. Digitization promises few overnight successes. It will take a comprehensive and sustained program along with many collaborating partners to open North Carolina's secure storage, unlock its closed stacks, and bring the digital surrogates of the state's special items to the people. NC ECHO is a first step in that comprehensive and sustained program. 


\section{References}

${ }^{1}$ For a good list of other statewide digitization projects around the country, see the Web site Collaborative Digitization Projects in the United States, which is maintained by Ken Middleton at Middle Tennessee State University and located at http://www.mtsu.edu/ kmiddlet/stateportals.html (viewed on Oct. 8, 2004). NC ECHO was the second statewide digitization program in the nation, following the Colorado Digitization Project (CDP). It grew out of Building Libraries-A Plan for Library Cooperation, which was adopted by the State Library Commission on June 14, 1999. Duke University's Library has played a significant role in the creation of $\mathrm{NC} \mathrm{ECHO,} \mathrm{first} \mathrm{serving} \mathrm{as} \mathrm{a} \mathrm{found-}$ ing partner and then providing its University Librarian David Ferriero as the first chair of the advisory body, the Access to Special Collections Work Group.

${ }^{2}$ In Mar. 2000, a conference of approximately 100 representatives from North Carolina's cultural heritage repositories met in High Point to discuss the creation of a statewide access to special collections. The attendees at this conference gave NC ECHO its four major objectives: portal, standards, education, needs assessment. Since that time, a fifth objective has been added to the list: meeting the needs of the state's school children. NC ECHO has explored the last objective through partnerships with the North Carolina Center for the Advancement of Teaching (NCCAT), LearnNC, and the North Carolina Department of Public Instruction.

3 The University of North Carolina at Chapel Hill's Documenting the American South Web site is located at http://docsouth.unc.edu/.

${ }^{4}$ Duke University's Papyrus Archive is located at http:// scriptorium.lib.duke.edu/papyrus/texts/homepage.html

5 East Carolina University's North Carolina History and Fiction Digital Library is located at http://www.lib.ecu.edu/ncc/historyfiction/.

${ }^{6}$ Union County Public Library's Heroic Sons of Gold Star Mothers Scrapbook is located at http://www.union.lib.nc.us/genealogy.htm

${ }^{7} \mathrm{NC}$ ECHO is currently exploring the use of Blue Angel Technology for its centralized search and retrieval tool. Other options being discussed have included those that have an Open Archives Initiative (OAI) component.

8 NC ECHO, "Digitization Guidelines" Working Draft, February 2004, viewed on Oct. 11, 2004, available at http://www.ncecho.org/Guide/2004/ toc.htm.

${ }^{9}$ For more information on TEI, see http://www.tei-c.org/. TEI can also be used to make so-called "smart" documents, or publications in which proper names or place names can be easily identified through a search mechanism.

10 A number of choices can be made within the guidelines of EAD. To aid close interoperability within the state, some of these choices have already been made by a consortium of EAD users, now a working group within NC ECHO. This set of choices (and the working group) have been dubbed, "NCEAD." For more on EAD, see http://www.loc.gov/ead/, and for more on NC EAD, see http://www.ncecho.org/ncead/.

11 One metadata scheme for works of art is the Categories for the Description of Works of Art (CDWA) developed by the Getty Art Museum. For more information on CDWA, see http://www.getty.edu/research/ conducting research/standards/cdwa/

12 For more information, consult the Dublin Core Metadata Initiative's Web site, available at http://dublincore.org/

13 NC ECHO sponsors a Dublin Core working group, NC-DC; an EAD working group, NC-EAD; and, along with the North Carolina Museum's Council, a museum object metadata working group. There is currently no national or international metadata standard for museum artifacts.

14 These templates may be found on the NC ECHO metadata template Web site located at http://www.ncecho.org/dztools.asp

15 One of NC ECHO's first core principles was the conviction that digitization rests upon the solid foundation of traditional arrangement, description, and preservation activities. As more than one NC ECHO-sponsored program 
has emphasized, "Digitization is not a replacement activity." Because one makes a digital copy of an item does not mean that the original need not be cataloged, etc.

${ }^{16}$ Some of NC ECHO's grant programs require that at least one staff member from a recipient institution attend the Digitization Institute.

17 For more on NC ECHO's continuing education activities, see NC ECHO Continuing Education page located at http://www.ncecho.org/conted/ continuing education template.asp The State Historical Records Advisory Board recently received a federal grant to create "archives boot camps" for volunteer-run and other small agencies in the state. Because of this, the Hometown History workshops have changed their focus.

18 This survey instrument was modified to provide categories for museum responses and state of digitization activities and is located at http:// www.ncecho.org/travelog/SurveyForm081500.htm

${ }^{19}$ Scott Reavis left NC ECHO for another position and was replaced by Donna Baker. NC ECHO is currently again without a project librarian. As a result, much of the survey has been completed by Kim Cumber. For more information about NC ECHO's survey, see "North Carolina ECHO, The Survey" located at http://www.ncecho.org/travelog/travelog.asp

${ }^{20}$ Most of the grants ranged between $\$ 6,000$ and $\$ 7,000$ in this category in 2004-2005. The total amount awarded in 2004-2005 Starter Grants was $\$ 43,303$.

21 The total amount awarded in this category in 2004-2005 was $\$ 272,635$.

22 The provision of the online interpretive/contextual material is simply a more formalized practice of what librarians and archivists have always done informally at their reference desks and in the stacks.

${ }^{23}$ Members of the work group include Robert Busko, Director, Scotland County Public Library (liaison to the State Library's LSTA Advisory Committee); Robert Byrd, acting director of Duke University Libraries; Kevin Cherry, Visiting Instructor, East Carolina University's Dept. of Library Science and Instructional Technology; Joseph Coving, Director of Education, North Carolina Museum of Art; Martha Battle Jackson, Registrar, North Carolina Historic Sites; Hal Keiner, University Archivist, Appalachian State University; Dick Langford, State Archivist; Eileen McGrath, Collections Management Librarian, North Carolina Collection, UNC-CH; David Smith, Media/Technology Coordinator, North Carolina Center for the Advancement of Teaching; Gerry Solomon, Asst. Section Chief, Evaluation Services, North Carolina Department of Public Instruction; Helen Wykle, Special Collections, D.H. Ramsey Library, UNC-Asheville. Resource members: Steve Hensen, Director of Planning and Project Development, Rare Book, Manuscripts and Special Collections Library, Duke University; Druscie Simpson, Division of Archives and History, Archives and Records Section. State Library Staff: Sandy Cooper, State Librarian and Grant Pair, Asst. State Librarian for Information Technology. NC ECHO staff: Peggy Schaeffer, project manager; Kim Cumber, project archivist; and Kathy Wisser, metadata coordinator.

\section{About the Authors}

Thomas Kevin B. Cherry

Position: Visiting Instructor, Department of Library Science and Instructional Technology, College of Education, East Carolina University

Education: B.S. Biology, M.A. History, M.S.L.S., Ph.D. candidate, University of North Carolina at Chapel Hill

Wiley J. Williams

Position: Professor Emeritus of Library Science, George Peabody College for Teachers (now part of Vanderbilt University), and Professor Emeritus of Library Science, Kent State University

Education: B.S., University of North Carolina, M.L.S., George Peabody College for Teachers, M.P.A.(Master of Public Administration), Ph.D., University of Michigan. 